\title{
Research Paper \\ The Structural Model of Social Skills in Children with Learning Disabilities based on the Attachment Styles: The Mediating Role of Academic Self-efficacy
}

\author{
Mahdi Khoda Bakhsh ${ }^{1}$, Hadi Hashemi Razini ${ }^{* 2}$, Robabeh Nouri Ghasemabadi ${ }^{3}$ \\ 1. Ph.D. Student, Department of Psychology, Saveh Branch, Islamic Azad University, Saveh, Iran
}

2. Assistant Professor, Department of Psychology, Faculty of Psychology and Education, Kharazmi University, Tehran, Iran

3. Associate Professor, Department of Psychology, Faculty of Psychology and Education, Kharazmi University, Tehran, Iran

Citation: Khoda Bakhsh M, Hashemi Razini H, Nouri Ghasemabadi R. The structural model of social skills in children with learning disabilities based on the attachment styles: the mediating role of academic selfefficacy. J Child Ment Health. 2021; 8 (1):1-13.

URL: http://childmentalhealth.ir/article-1-1063-en.html
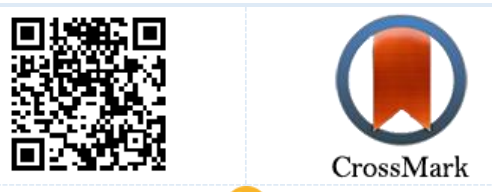

$10.52547 / \mathrm{jcmh} .8 .1 .2$ (2) $20.1001 .1 .24233552 .1400 .8 \cdot 1 \cdot 3.2$

\section{A R T I C L E I N F O}

Keywords:
Social skills,
attachment style,
academic self-efficacy,
learning disabilities

Received: 31 Aug 2020

Accepted: 7 Mar 2021

Available: 8 Jun 2021

\begin{abstract}
A B S T R A C T
Background and Purpose: Learning disabilities affect many aspects of a person's life, including social skills. And, most children with poor social skills are depressed and isolated. Therefore, this study aimed to develop a structural model of social skills in children with learning disabilities based on their attachment styles, through the mediating role of academic self-efficacy.

Method: The present study was an applied research in its objective and a survey-correlational study using structural equations in the method of gathering the data. A sample of 200 students with learning disabilities referring to Bujika Center for the Treatment of Learning Disabilities in Tehran in 20192020 were selected by convenience sampling. The Social Skills Rating System-Parents Version (Gresham \& Elliott, 1990), the Kinship Center Attachment Questionnaire (Halpern \& Kappenberg, 2006), and the Academic Self-Efficacy Scale (Jinks \& Morgan, 1999) were used to collect data. Research data were analyzed by structural equation modeling and mediation effect testing in the proposed model using bootstrap method.

Results: Findings showed that the proposed model was fitted to the data. Based on the results, anxious and avoidant attachment styles and academic self-efficacy were negative and positive predictor of social skills, respectively $(\mathrm{p}<0.05)$. Findings also confirmed the mediating role of academic self-efficacy in the relationship between anxious and avoidant attachment styles and social skills.

Conclusion: Therefore, it can be concluded that anxious and avoidant attachment styles decrease the social skills in children with learning disabilities, while the indirect effect of attachment styles through the mediating role of academic self-efficacy improves the social skills in these children.
\end{abstract}

* Corresponding author: Hadi Hashemi Razini, Assistant Professor, Department of Psychology, Faculty of Psychology and Education, Kharazmi University, Tehran, Iran.

E-mail: Hadihashemirazini@yahoo.com

Tel: (+98) 2188329220

2476-5740/ (C) 2021 The Authors. This is an open access article under the CC BY-NC-ND license

(https://creativecommons.org/licenses/by-nc-nd/4.0/). 


\section{Extended Abstract}

\section{Introduction}

Learning disabilities (also known as specific learning disorder) refers to a neurodevelopmental disorder with biological origin which forms the basis of cognitive abnormalities associated with the behavioral symptoms of this disorder. Most specialists and psychologists have pointed out three main categories of learning disabilities, including dyslexia, dysgraphia and dyscalculia (1). Diagnosis is made when the individual shows specific deficits in the perceptual or processing ability (2). Learning disabilities influence several aspects of an individual's life, including social skills; in such a way that many children and students with poor social skills are depressed and socially isolated (5).

Study shows that social skills deficit negatively affects different dimensions of a student's life (7). Meanwhile, attachment styles are probably among the important factors influencing the social skills of learners. Three major attachment styles include the secure, the anxious/ ambivalent, and the avoidant (8). Many attachment theories argue that the way the children are attached to their caregivers, specifically the parents, is profoundly associated with their social skills in the school (12\& 13). For example, Tajik Esmaieli \& Torbati (2021) showed that the attachment styles are significantly related to the social skills of students (11). Alongside, Caplan, Morgan, Noroña, Tung, Lee, \& Baker found that social skills in children are influenced by the early life childcaregiver relationships and if a child is deprived of proper care during the critical period of growth, he or she will have problems in experiencing intimacy and social skills during the adulthood (13).

Another construct recently addressed by mental health professionals is self-efficacy. Self-efficacy is a personal judgment on how well or poorly a person is able to cope with a given situation and it affects different levels of intellectual, behavioral, and emotional patterns (15). Academic self-efficacy has been addressed as an outcome of optimal social skills (19) and it has been known a predicator of study quality (20). Researchers believe that academic selfefficacy is associated with the social skills in children (20\& 24) and it plays a mediating role in the relation between attachment and social skills (16). For example, Smith, Williams, O'Donnell, and McKechnie showed that academic self-efficacy acts as a mediator between attachment styles and social skills (16).

Keeping in mind the foregoing issues, considering the significance of identifying the factors influencing the social skills in the students with learning disabilities, and taking into account this fact that no study has yet investigated these factors in an integrated model, efforts were made here to determine the structural model of social skills in the children with learning disabilities based on their attachment styles, with the mediating role of academic selfefficacy.

\section{Method}

The present study was a survey-correlational study using structural equation modeling to investigate simultaneously the relations between the variables in a model. The population included all the first to fifthgrade students with learning disabilities (dyslexia, dysgraphia, and dyscalculia) who had referred to Bujika Center for the Treatment of Learning Disabilities in Tehran in 2019-2020. A sample of 200 students was selected from this population by convenience sampling. The inclusion criteria were diagnosis of learning disabilities in Bujika Center, lack of any other concomitant disorder, written consent by the students and the parents, and normal intelligence; while exclusion criterion was lack of motivation in the parents to fill the questionnaires. Data were collected by Social Skills Rating SystemParents Version (25), Kinship Center Attachment Questionnaire (28) and Academic Self-Efficacy Scale (30). The collected data were analyzed by SPSS 26 and AMOS 24.

\section{Results}

Regarding the results of correlation matrix, there was a significant negative correlation between avoidant and anxious attachment styles and academic selfefficacy $(\mathrm{P}<0.01)$. The correlation between secure attachment style and self-efficacy and that between self-efficacy and social skills were significant and positive $(\mathrm{P}<0.01)$. To explore the relationship fitting, structural equations modeling in the form of path 


\section{Quarterly Journal of}

Child Mental Health

Vol. 7, No. 4, Winter 2021

analysis was used. The determination coefficient of social skills in the modified structural model was 0.540 , indicating that the extraneous and mediating variables; i.e. the attachment styles and self-efficacy, can explain $54 \%$ of the variation in social skills which is more than he average amount. Results of Bootstrap quiz showed that the indirect effect of avoidant and anxious attachment styles on social skills through the mediating role of self-efficacy was -0.1540 and -0.0761 , respectively; which was statistically significant. But, the indirect effect of secure attachment style on social skills through selfefficacy was not significant.

\section{Conclusion}

This study was conducted to establish the structural model of social skills in children with learning disabilities based on their attachment styles, through the mediating role of academic self-conception. Results implied that attachment styles are associated with social skills in these children. Also, it was found that avoidant and anxious attachment styles are negative predicators of social skills in children with learning disabilities, while secure attachment style is a positive predicator of social skills. These results were in consistency with several researches $(11,12$, 13), indicating that early life child-caregiver relationship affects the social skills in children. Another finding resulting from carrying out the model was that academic self-efficacy mediates the relation between attachment style and social skills. Put it in another way, attachment styles positively affect social skills in children with learning disabilities through the mediating role of academic self-efficacy. This coincides with Smith, Williams, O'Donnell, and McKechnie (16), arguing that academic self-efficacy acts as a mediator between attachment styles and social skills.

In explaining the above findings, it can be said that when a person believes in his individual and academic abilities, he can overcome the negative feelings originated from insecure attachment and dare to have social and interpersonal relationships. On the other hand, high academic self-efficacy and good performance in the school can extend the student's communication with others, which in turn may encourage the student with insecure, avoidant, or anxious attachment style to have social communication with others. It is worth mentioning that social skills in children are affected by the early life childcaregiver relationship; hence enhancing the social skills in people with learning disabilities requires the change of attachment style in them. Also, it can be explained that people with secure attachment style share their thoughts and feelings more easily, resulting in their empathy with others. Therefore, the healthy early life child-caregiver relationship leads to secure attachment style, which in turn develops the social skills in the individual. So, the person can perform better in interpersonal relationships, problemsolving, decision making and social adjustment. Among the limitations of this study, we can mention its being carried out on only one gender. Also, parent-version questionnaire was used which may have prevented some individuals from giving their real answer. Therefore, using the teacher-version questionnaire is also suggested. Besides, the parental level of study and economic status of the family were not controlled in this study, although they may influence the parenting styles. It is suggested that next studies limit the parental level of study and economic status of the family.

\section{Ethical Considerations}

Compliance with ethical guidelines: This study was conducted the necessary scientific and executive licenses from Islamic Azad University (Saveh branch) and the Education administration. Also, the consent of the participants was gained and the principles of privacy and confidentiality were observed

Funding: The present study was conducted by the authors with no financial support.

Authors' contribution: This study was extracted from the Ph.D. thesis of Mehdi Khoda Bakhsh in the field of psychology at Saveh Branch of Islamic Azad University, supervised by Dr. Hadi Hashemi and advised by Dr. Robabeh Nouri.

Conflict of interest: This study was conducted with no conflict of interest and the results have been reported vividly with no bias.

Acknowledgments: The authorities of Bujika Center for the Treatment of Learning Disabilities in Tehran, the participating students and their parents are sincerely appreciated. 


\title{
الكوى ساختارى مهارت اجتماعى كود كان با ناتوانىهاى ياد يرىى بر اساس سبكىهاى دلبستكى با نقش واسطهاى خود كار آمدى تحصيلى
}

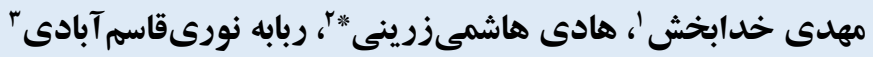

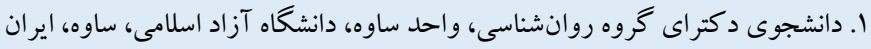

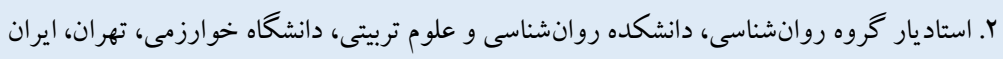

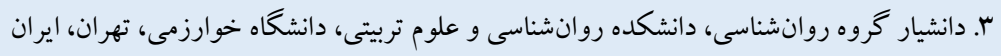

زمينه و هدف: ناتو انى هاى يادگيرى عاملى مؤثر بر بسيارى از جنبه هاى زندگى فرد از جمله مهارت اجتماعى است، به گونهاى كه عمده

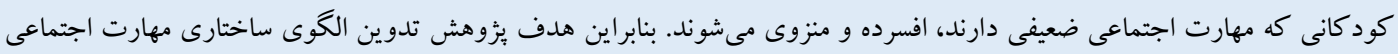

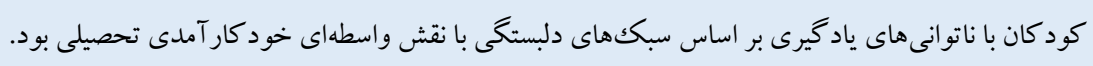

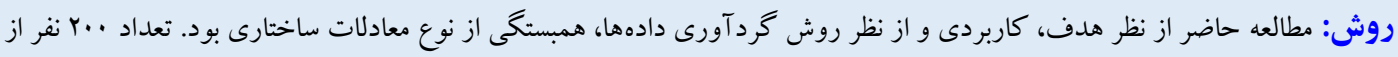

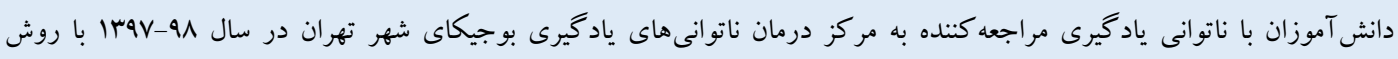

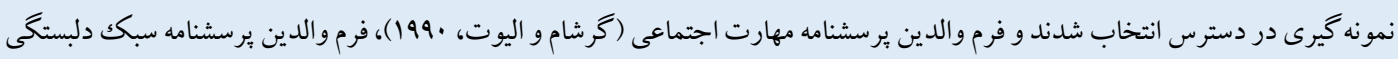

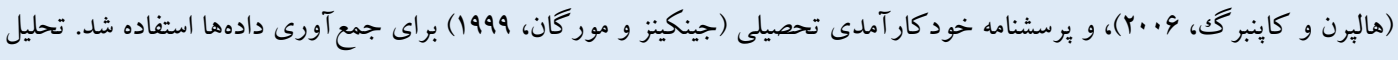

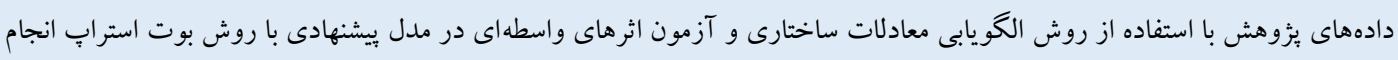

يافتهها: برآيندها نشان دادند كه الكوى ييشنهادى از برازش خوبى با دادهها برخوردار است. بر اساس نتايج، سبكهاى دلبستخى اجتنابى و

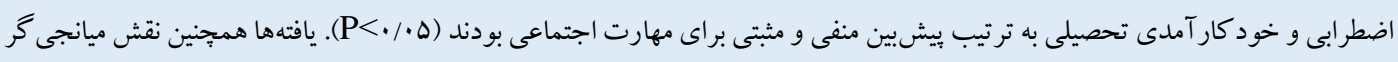

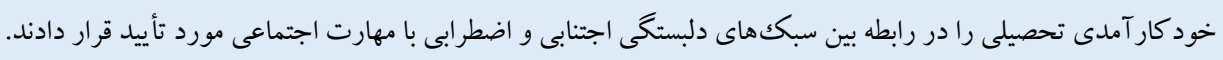
نتيجه كيرى: نتايج نشان دادند كه سبك هاى دلبستخى اجتنابى و اضطرابى موجب كاهش مهارتهاى اجتى اجتماعى در كود كان با ناتوانى هاى

دريافت شده: ·

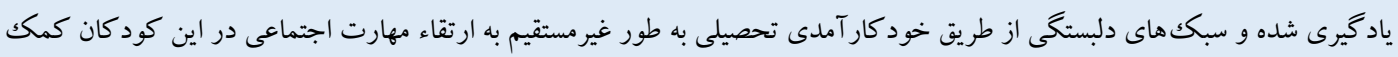

مشخصات مقاله

كليدوازهها:

مهارت اجتماعى،

سبك دلبستخى،

خود كار آمدى تحصيلى،

ناتوانى ياد گيرى

مى كند.

يذيرفته شده:

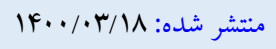

* نويسنده مسئول: هادى هاشمى زرينى، استاديار گروه روانشناسى، دانشكده روانشناسى و علوم تربيتى، دانشگاه خوارزمى، تهران، ايران.

Hadihashemirazini@yahoo.com : رايانامه

تلفن: MNMrarr. 
تأثير مى گحذارنـد، احتمـال دريافت تقويت اجتماعى رابه بيشـترين حد

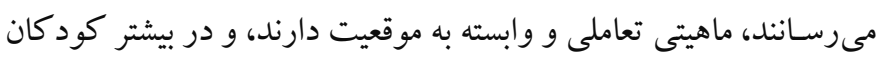
از طريق تعامل با والدين شكل مى گيرند (9).

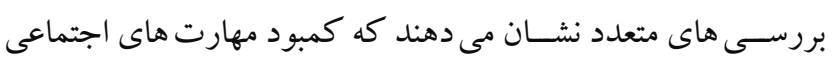

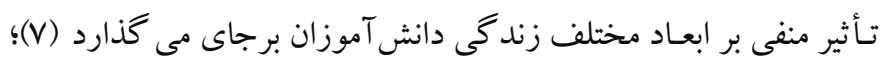

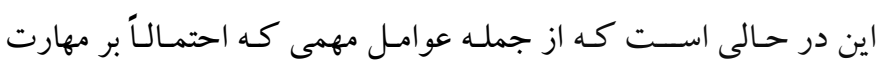

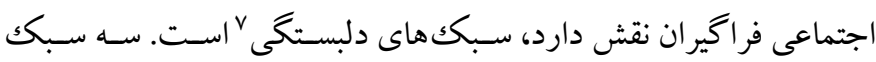

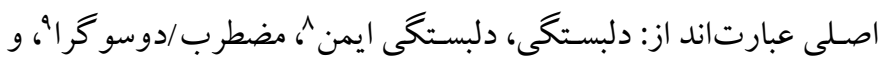

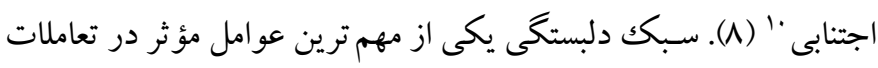

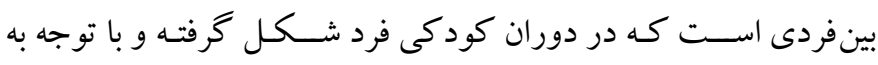
محيطى كه در آن تحول يافته اســت، در ســـين بعدى ادامه مى يابد. در واقع، سبككهاى دلبستيخى از طريق مدل هاى فعال درونى بر نحوه اسـناد

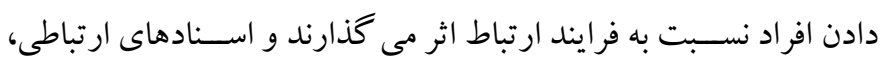
داراى بتانسيل واسطه گرى بين سبك هاى دلبستخى و كيفيت رابطه هستند

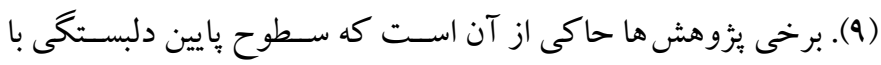

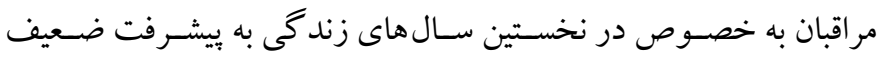

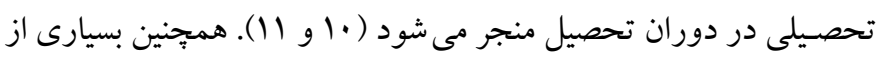

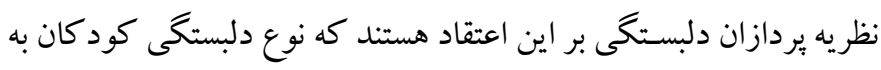

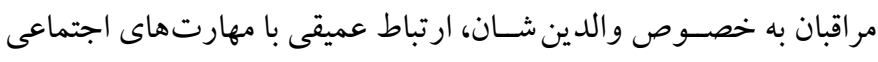

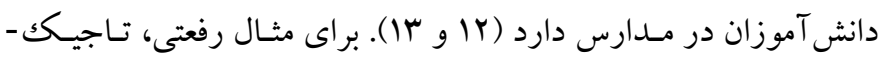

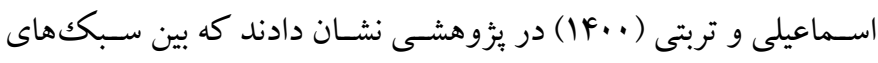
دلبسـتخى با مهارت هاى ارتباطى افر اد در دوران تحصسيل، ارتباط معنادار

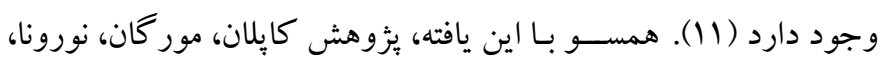

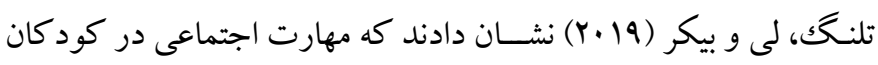

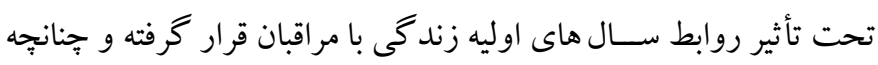

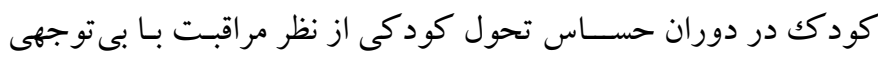

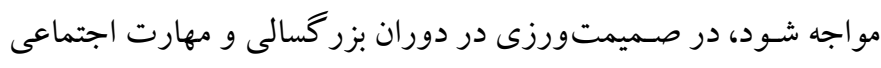

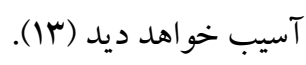

6. Social skill

7. Attachment styles

8. Secure

9. Anxious/ambivalent

10. Avoidant
مقلهم امروزه دانش آموزان از اركان اصــلى نيروى انسـانى كشــور محســوبـ مىشـوند و نقشسى فراوانى در تحول، يِيشـفت، و تعالى كشـور دارند. از اين رو، توجه به سـلامت و سرزندكى روانى - اجتماعى و تحصيلى آنها به ويزه فراگيران با ناتوانىهاى ياد گيرى از اهميت ويثزاى برخوردار اســ؛ بنـابر اين همواره برنامهريزان، مديران، معلمان، و والدين اين دانش آموزان

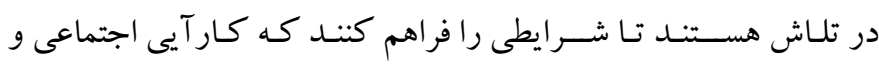
تحصيلى آنان بالا برود.

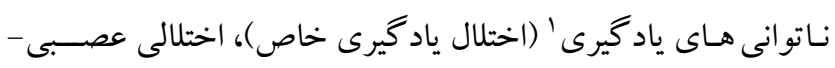
تحولى با منشـأ زيسـتى بوده و مبنايى اسـت براى نابهنجارى ها در سـطح شـناختى كه با علائم رفتارى اين اختلال ارتباط دارند. اغلب متخصصان و روانشناسان به سه طبقه اصلى در اين دسته از اختلالات اشاره كردهاند كه

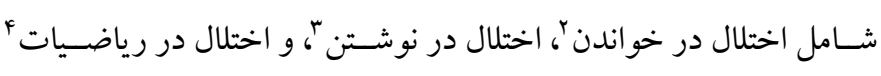
اسـت ( (1). اين اختلال زمانى تشـخيص داده مى شـود كه فرد كمبودهاى خاصسى در توانايى دركك يا بردازش داشـهـ باشـــ (Y). ينجمين ويراسـت

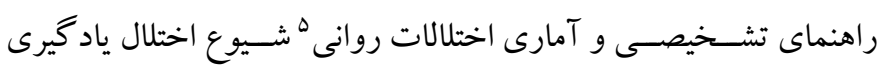
خاص در زمينه هاى تحصسيلى را بين ها تا ها درصـد در كود كان دبستانى

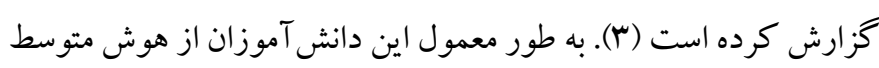
يا بالاتر برخوردارند ولى در شــرايط يكســان آموزشـى نسـبت به ديخر دانش آموزان، عملكرد تحصـيلى ضـعيف ترى نشـان مى دهند و با وجود

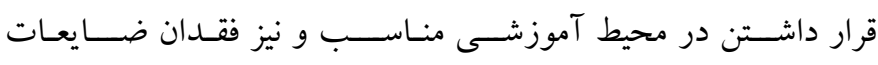
زيست شناختى آشكار، عدم مشكلات اجتماعى و روانى حاد، و با داشتن هوش متوسـ، قادر به ياد گيرى در زمينه هاى خاص (خواندن، نوشـن، و محاسبd) نيستند (ساو F) ناتوانى هاى ياد گيرى عاملى مؤثر بر بسـيارى از جنبه هاى زندگى فرد از جمله مهارت اجتماعى "اســت، به كونه اي كه عمده دانش آموزان و كود كانى كه مهارت اجتماعى ضـعيف دارند، افسـدهه و منزوى مى شوند (ه). مهارت هاى اجتماعى رفتارهاى آموختنى هســتند كه بر روابط افراد

1. Learning disabilities

2. Dyslexia

3. Disorder of written expression

4. Mathematics disorder

5. Diagnostic and statistical manual of mental disorders, fifth edition (DSM-V) 
با توجه به مســائل مطرح شــلهه و اهميت شــناســايى عوامل مؤثر بر مهـارت اجتمـاعى دانش آموزان بـا نـاتوانىهـاى يـاد گيرى و براســـاس يزٔوهش هاى انجام كرفته در اين حوزه كه روابط دو به دو اين متغيرها را بررسى كردهاند و تاكنون بثوهشى كه بتواند در يكك مدل منسجم، اين متغيرها را مورد بررسـى قرار داده باشــ، انجام نشـده اســ؛ در نتيجه اين بزوهش بـا هـدف تعيين الكوى ســاختـارى مهارت اجتماعى كود كان با ناتوانىهاى ياد گيرى بر اسـاس سـبك هاى دلبسـتخى با نقش واسـطهاى خود كار آمدى تحصيلى انجام شد.

روش الف) طرح هزوهش و شــ كت كنند كان: روش يُزوهش حاضر از نوع

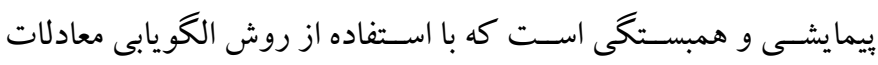

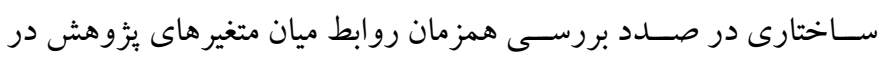

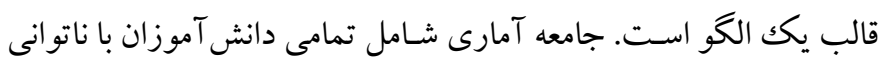

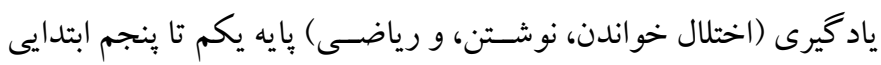

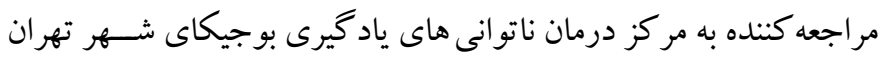

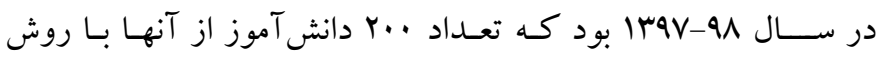
نمونه كيرى در دسترس به عنوان نمونه مورد مطالعه انتخاب شدهاند. للازم

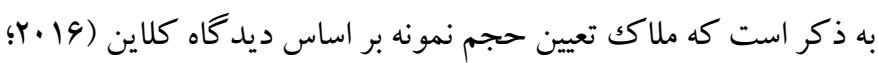

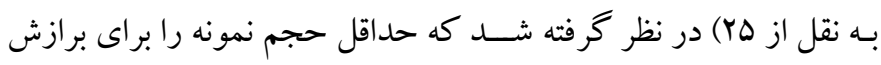

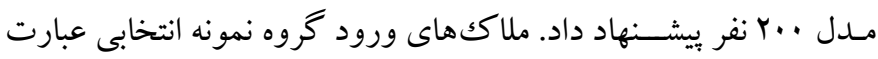

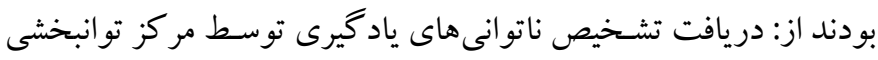

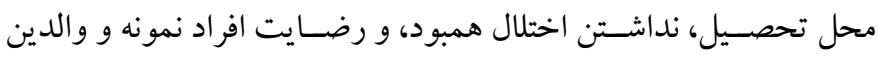

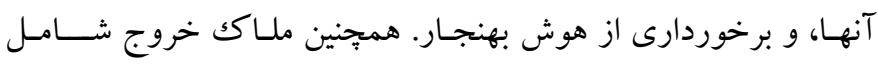

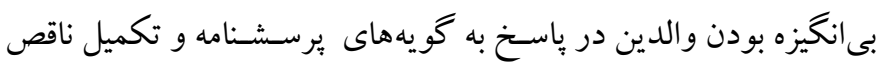
آن در نظر كرفته شد.

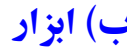

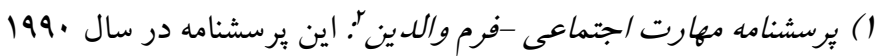

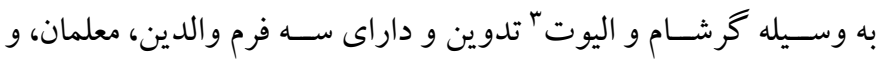

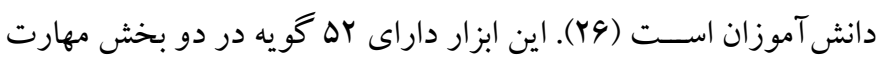

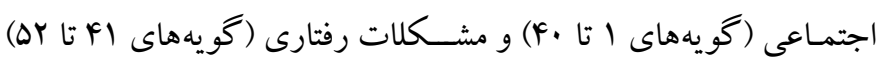

از ديخر سـازه ها كه در جِند سـال اخير مورد توجه متخصصان حوزه

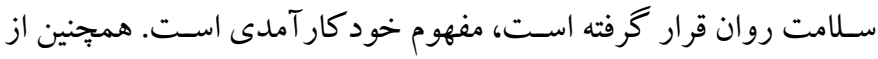

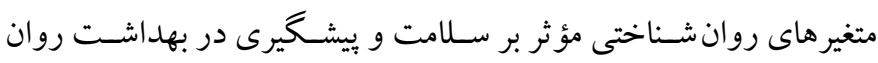
بيمـاران مزمن و مشــكلـات عـاطفى - رفتـارى در كود كـان و نوجوانـان

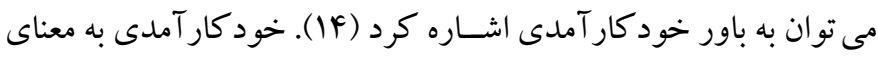

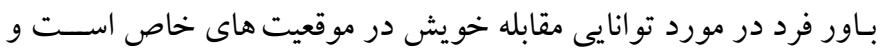

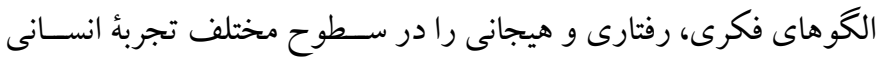

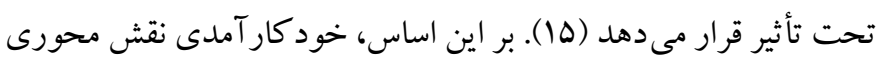

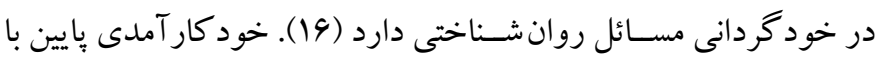

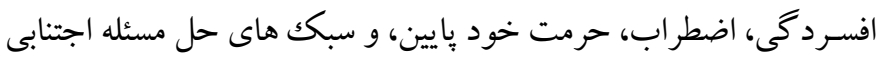

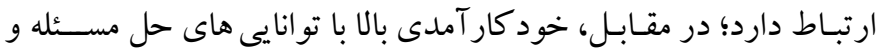

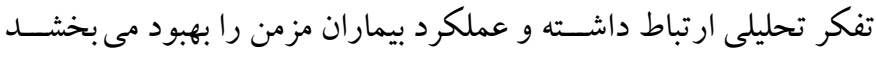

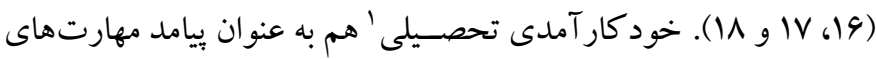

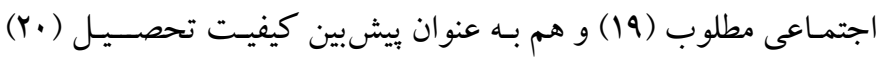

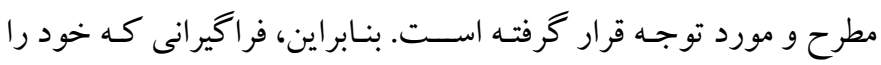

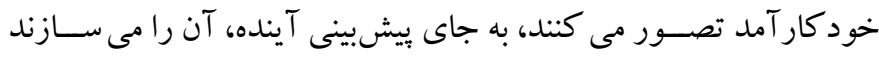

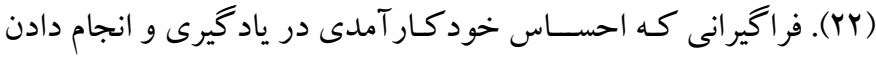

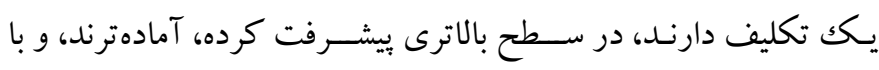

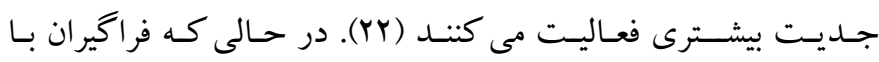
خو كار آمدى سـطح بايين ممكن اسـت حتى براى يكك امتحان خودشان

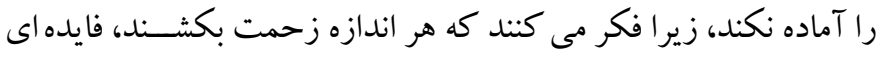

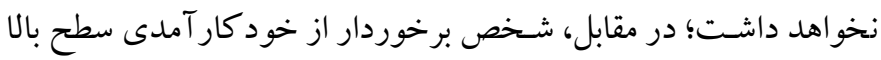

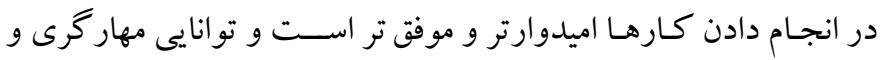

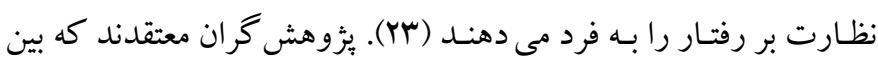

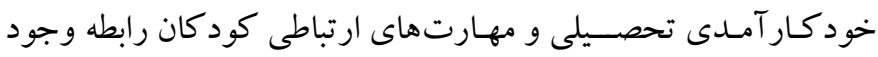

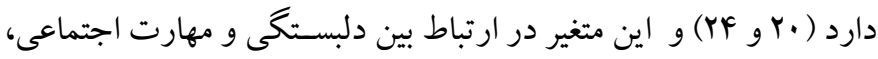

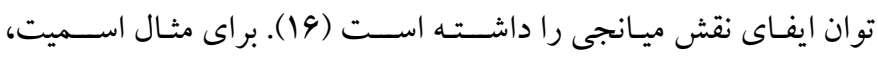

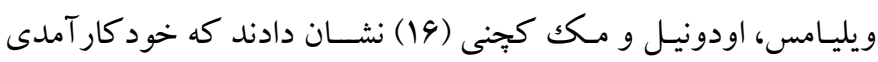
تحصسيلى بين سبكك دلبستخى و مهارت هاى اجتماعى نقش ميانجيكرانه

دارد (19). 
موافقم= نمره F) محاسبه مى شـوند كه كسب نمره بيشتر در اين مقياس به

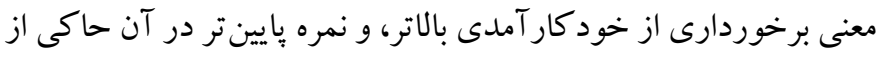

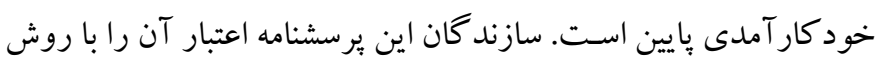

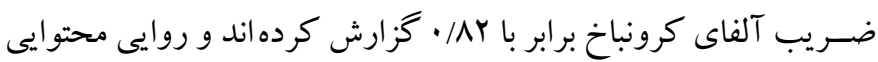

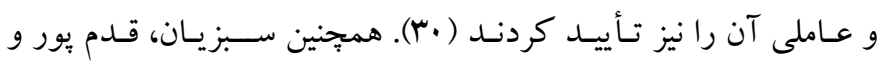

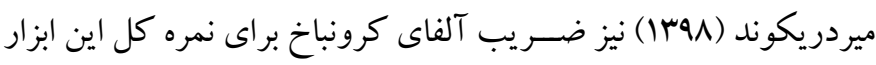

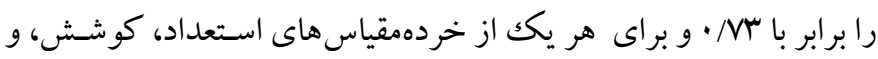

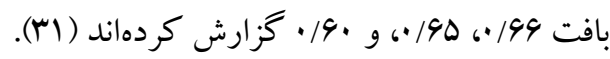
ج) روش اجرا: بس از دريـافت مجوزهـاى لـازم و همـاهنكَى بـا مركز

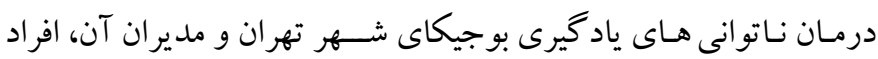

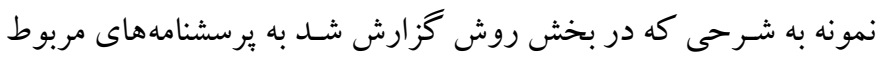

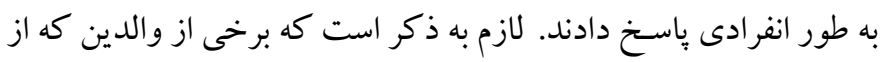

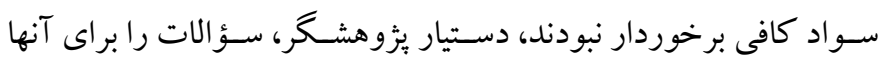

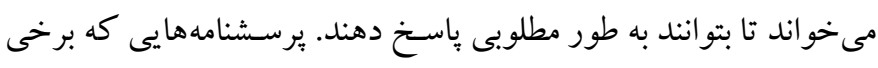

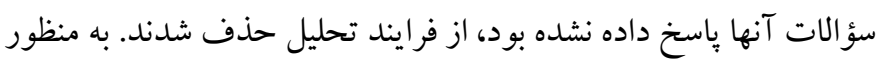
فراهم آوردن محيطى مناســب جهت اجر اي مطلوب ئزوهش و بالا بردن

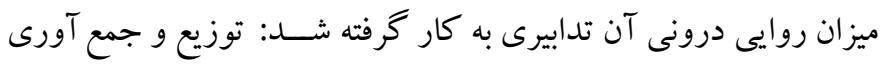

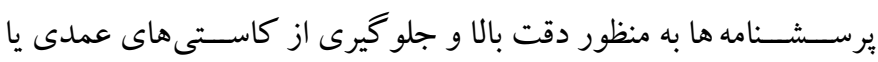

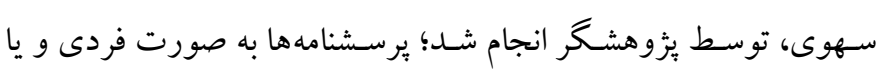

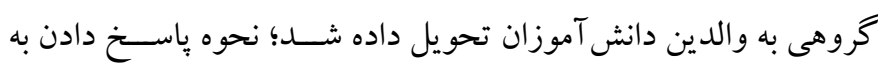

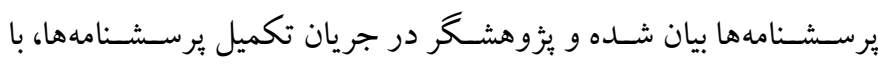

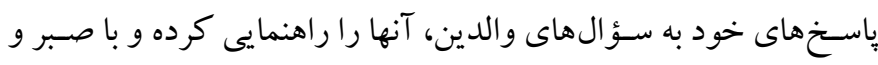
حوصـله به رفع ابهام برداخت؛ زمان توزيع برســـــــامه مدتى قبل از تمام

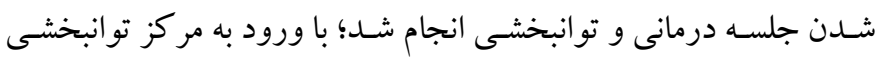

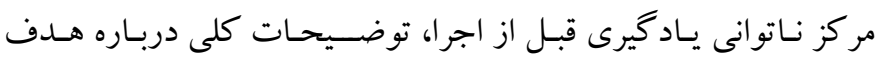

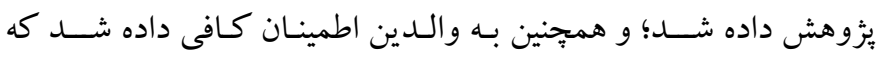

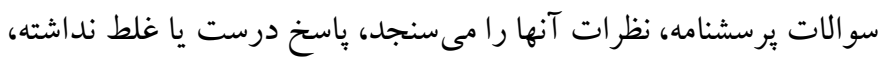

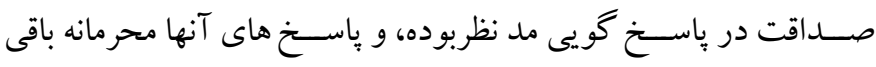

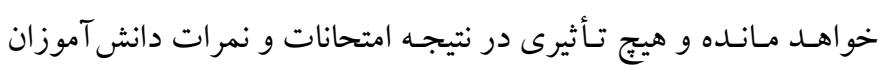

3. Academic self-efficacy scale 4. Jinks \& Morgan
اسـت. در اين بثروهش، بخش مهارت هاى اجتماعى اسـتفاده شد كه يكك

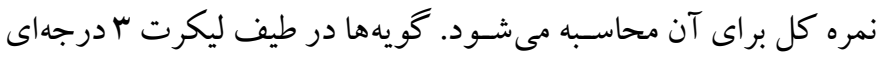

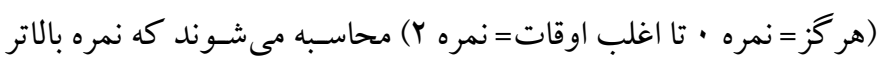

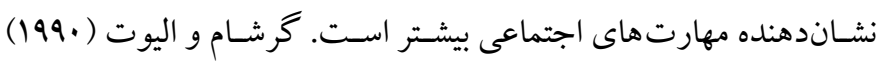

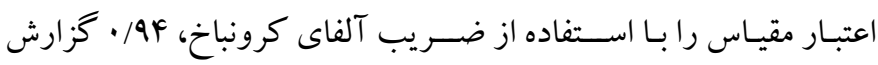

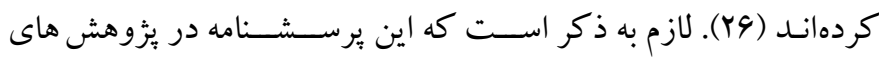

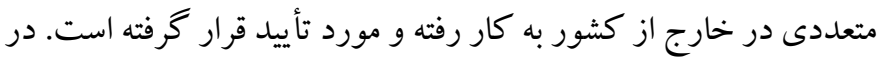

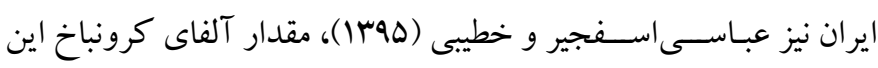

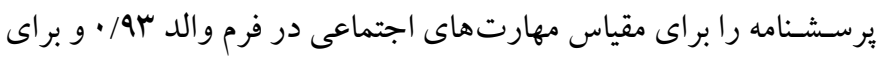

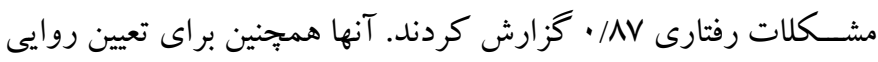
يرسشـنامه از روايى محتوايى و روايى سـازه استفاده كردند. نتايج تحليل

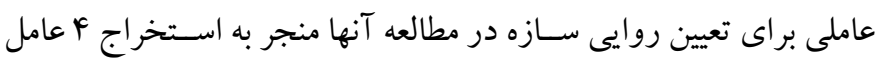

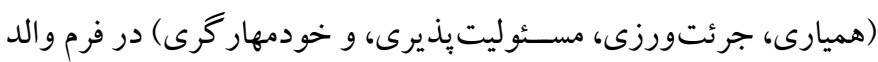

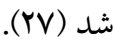

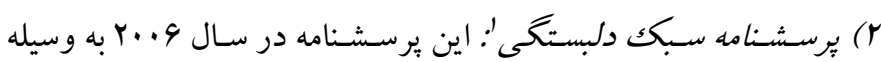

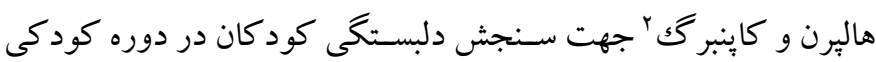

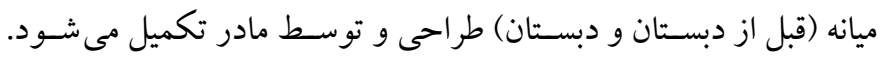

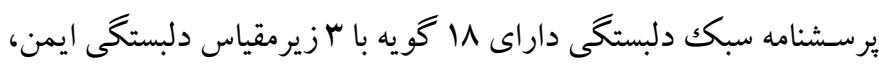

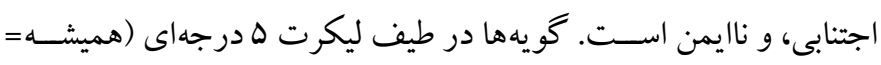

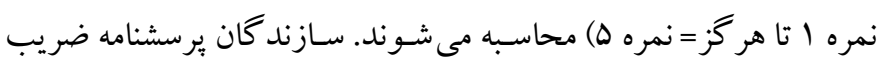

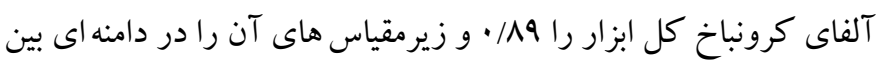

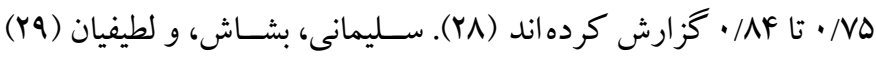

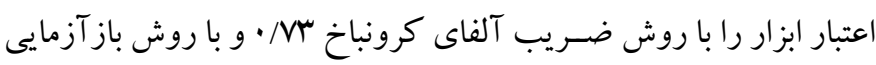

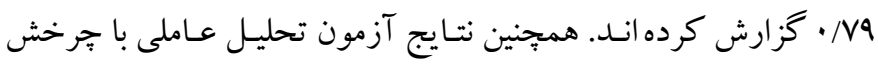

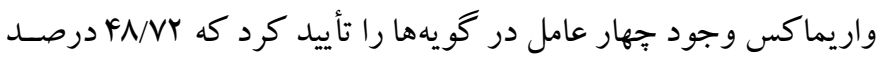
از واريانس كل مقياس را تبيين كردند ( (Y)).

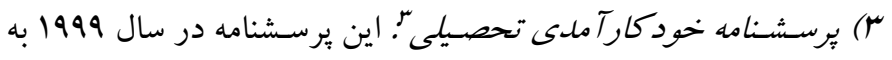

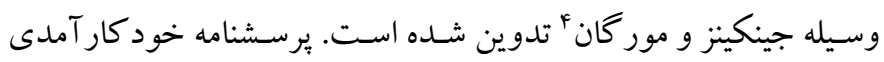

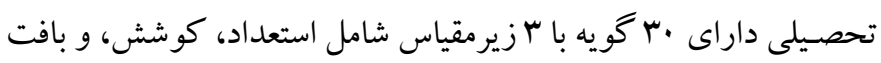

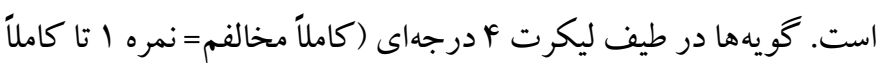

1. Kinship Center Attachment Questionnaire

2. Halpern \& Kappenberg 


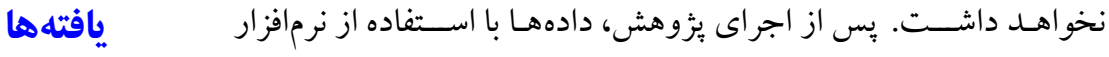
در جدول ا شـاخص هاى توصيفى متغيرها شامل ميانگين، انحر اف معيار، و و $\mathrm{SPSS}_{26}$ جولكى، و كشيدگى گز ارش شدهاند.

جدول 1: يافتهاى توصيفى متغيرهاى بزوهش

\begin{tabular}{|c|c|c|c|c|c|c|}
\hline كشيدكى & جولنى & انحر اف معيار & ميانكين & حداكثر & حداقل & متغير هاى بثزوهش \\
\hline$-1 / r 1$ & $\cdot /$ If & $r / v q$ & $G \pi / 4 D$ & $\wedge$. & · & مهارت اجتماعى \\
\hline$\cdot / \mathrm{WV}$ & $-\cdot / V Y$ &.$/ 94$ & $৭ \Delta / \wedge \vee$ & ir. & $r$. & خود كار آمدى \\
\hline$\cdot / r Y$ & $-\cdot / \Delta \Delta$ & $r / \Delta \Lambda$ & $|N / Y|$ & rq & 1. & سبك دلبستكى ايمن \\
\hline$\cdot / \mu$. & . & Y/AV & $19 / \cdot F$ & Yq & 1. & سبك دلبستكى اجتنابى \\
\hline$\cdot / 4 \Delta$ & - ( ) & $9 / \pi r$ & $I V / I \Lambda$ & $r$. & 9 & سبكك دلبستكى اضطر ابى \\
\hline
\end{tabular}

جدول r اطلاعات مربوط به همبسـتخى بيرسون بين سبك هاى دلبستخى، مهارت اجتماعى، و خود كار آمدى گزارش شده است.
بر اســاس نتايج به دســت آمده در جدول ا، ارزش هاى جولكى و كشـــــى نشــان مى دهد كه متغيرهاى بثزوهش، توزيع نرمال دارند. در

جدول ז: ماتريس همبستغى بين مهارت اجتماعى، خود كار آمدى و سبككهاى دلبستىى

\begin{tabular}{|c|c|c|c|c|c|}
\hline 0 & $\varepsilon$ & $r$ & r & 1 & متغيرهاى يزوهش \\
\hline & & & & 1 & ا. دلبستگى ايمن \\
\hline & & & 1 & $-\cdot / \wedge \mid \cdot * *$ & r. دلبستخى اجتنابى \\
\hline & & 1 & $\cdot / \mathrm{V} / * *$ & $-\cdot /$ V9১** & r. دلبستخى اضطر ابى \\
\hline & 1 & $-\cdot /$ NFF* & -•/Уฯ४** & $\cdot / v \cdot \kappa * *$ & F. خود كار آمدى \\
\hline 1 & - /VF. ** & $\cdot / \mathrm{V} \cdot * *$ & $-\cdot /$ V99** & $\cdot / 1 \cdot r$ & هـ مهارت اجتماعى \\
\hline
\end{tabular}

بر آورد مقادير كجى و كشـيدگى آزمون و تأييد شـدند. با توجه به اينكه دامنـه كجى و كشــــــى متغيرها در بازه بـ قرار داشــت، نرمال بودن تككمتغيرى مورد تأييد قرار گرفت. جهت بررسى نرمال بودن جندمتغيرى از ضـريب كشـيدگى استاندارد شده مرديا' و نسبت بحر انى استفاده شده

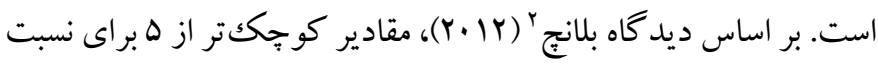
بحر انى بـه عنوان عسدم تخطى از نرمـال بودن جنــدمتغيره در نظر كرفتـه

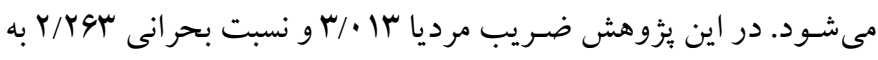
دســت آمــده كـه كمتر از عـدد ه اســـ؛ بنـابراين فرض نرمـال بودن جنــدمتغيرى برقرار اســت. جهـت بررسـى عـدم وجود دادههـاى پيرت
با توجه به نتايج ماتريس همبسـتِكى، بين سـبك دلبستّكى اجتنابى و اضــطر ابى بـا خود كـار آمـدى و مهـارت اجتمـاعى رابطه منفى و معنادار و و بين ســــك دلبســـى ايمن و خودكـار آمـدى، و بين خودكـار آمـدى و مهـارت اجتمـاعى رابطـه مثبـت و معنـادارى وجود دارد) در يزؤهش حـاضــر جهت بررســى برازش رابطه از روش مدل يابى معادلات سـاختارى در قالب تحليل مسـير استفاده شد. يِي از كاربرد اين روش، بررسى بيشفرضهاى اين شسيوه آمارى ضرورى است. بر اساس

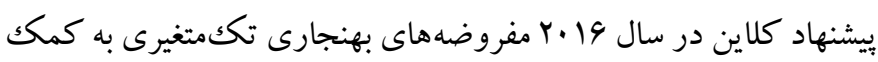


ميزان واريانس تبيين شـده متغيرهاى نهفته درونزا را نشـان مىدهد.

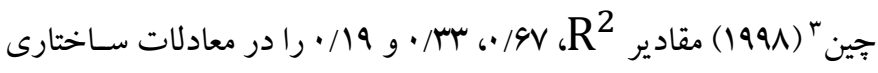
به ترتيب قوى، متوسط، و ضعيف توصيف مى كند. ضريب تعيين متغير

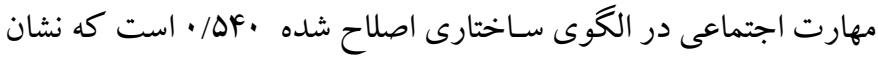

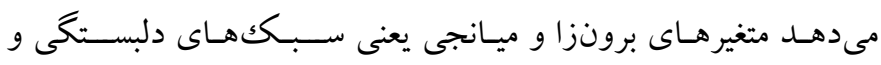

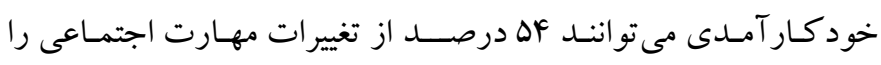

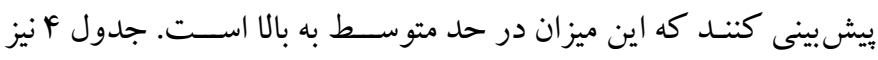

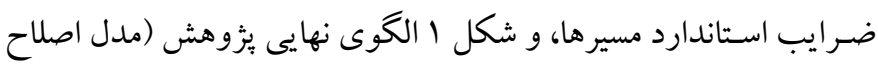

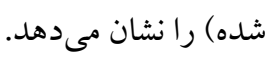

جندمتغيرى، شـاخص فاصـله ماهالانوبيس '، مورد بررسـى قرار گرفت و

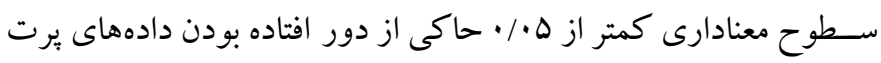
مورد نظر اسـت. بر اسـاس اين شـاخص، داده يرت شناسايى نشد. بنابراين

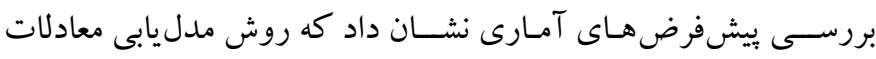
ساختارى در قالب تحليل مسير، روش مناسبى براى ارزيابى برازش مدل

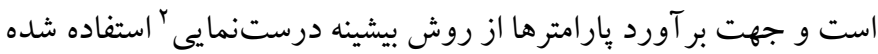
است (به نقل از (YD). نتايج شاخصدهاى برازش در جدول ب نشان مىدهد بعد از اصلاحات،

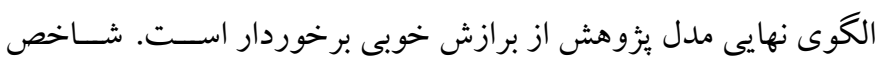

جدول r": شناسهاى برازش الكوى ييشنهادى و الكوى نهايى

\begin{tabular}{|c|c|c|c|c|c|c|c|c|c|c|}
\hline RMSEA & IFI & CFI & PNFI & PCFI & GFI & $\chi^{2} / \mathrm{df}$ & $\mathbf{P}$ & Df & $\chi^{2}$ & شناسه هاى برازش \\
\hline .1 .94 & - /Ars & - /Arq & $.19 .$. &.$/ 099$ & $\cdot / A V \mid$ & l/Ars & $<\cdot / \cdot \cdot 1$ & $r$ & $0 / 0.9$ & الخوى ييشنهادى \\
\hline.$/ .11$ &.$/ 991$ &.$/ 991$ & .191. & $\cdot / 9 \cdot \Delta$ &.$/ 991$ & $1 / \cdot r$. & . & 1 & $1 / \cdot r$. & الكوى نهايى \\
\hline
\end{tabular}

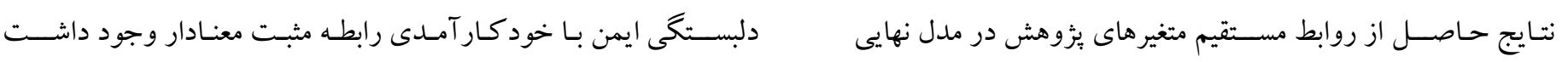

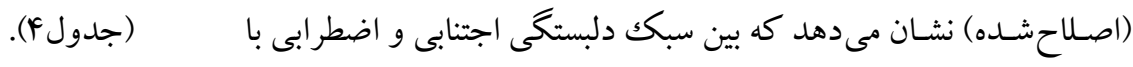

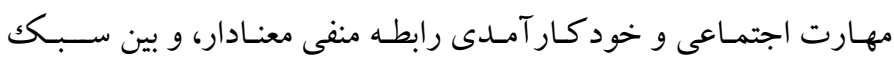

جدول ع: ضرايب استاندارد مسيرهاى الكوى نهايى (اصلاح شده)

\begin{tabular}{|c|c|c|c|c|}
\hline سطح معنادارى & 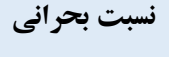 & خطاى معيار & ضرايب استاندارد & 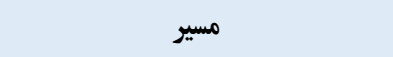 \\
\hline.$/$ ro & Y/ADS &.$/ .1$ & - & دلبستكى ايمن--->> خو دكار آمدى \\
\hline$<\cdot / \cdot \cdot 1$ & $-r / N F q$ &.$/ \cdot 1 r$ & $-\cdot|| f \mid$ & دلبستكى اجتنابى -->> خود كار آمدى \\
\hline$<\cdot / \cdot \cdot 1$ & $-F / \Delta$ Q & $\cdot / \cdot r 1$ & $-\cdot / \mu$ & دلبستىى اضطر ابى--->> خو كار آمدى \\
\hline ·/^९9 & $\cdot / r \Delta F$ &.$/ 1 F q$ & $\cdot / \cdot v^{f}$ & دلبستكى ايمن ---> مهارت اجتماعى \\
\hline$<\bullet / \cdot 1$ & $-r / ৭ \Delta r$ &.$/ 1$ & $-\cdot / M A F$ & 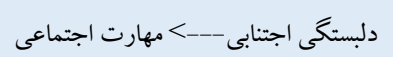 \\
\hline$<\cdot / \cdot 1$ & $-\psi / A \Lambda V$ &.$/ \cdot 19$ & $-\cdot / r \wedge$ & دلبستخى اضطر ابى_--> مهارت اجتماعى \\
\hline$<\cdot / \cdot \cdot 1$ & $\Delta / A \wedge$ & $\cdot / \cdot v$ & $\cdot / 4 \cdot$ & خود كار آمدى---> مهارت اجتماعى \\
\hline
\end{tabular}

3. Chin
1. Mahalanobis d-squared method

2. Maximum likelihood (ML) 


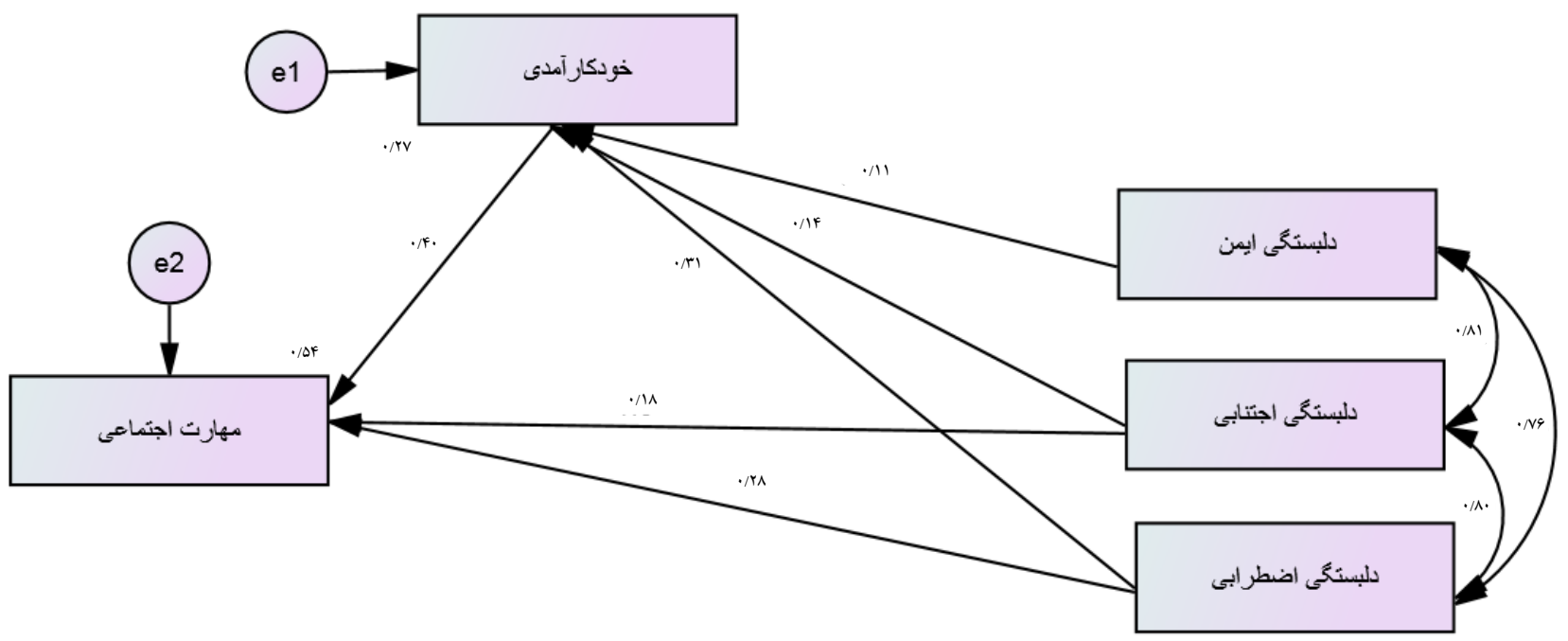

شكل ا: ضرايب استاندارد مدل التوى نهايى (اصلاح شده) رابطه ساختارى سبك هاى دلبستىى با مهارت اجتماعى از طريق ميانجيكرى خود كار آمدى در دانش آموزان

نتايج حاصل از روابط واسطهاى با اسـفاده از آزمون بوت استري در برنامه MACRO به جهت آزمودن مسـير واسطهاى در جدول ه نشان داده

جدول 0: آزمون ميانجى كرى روابط غير مستقيم به روش بوت استراب

\begin{tabular}{|c|c|c|c|c|c|c|}
\hline حد بالا & حد يايين & خطاى معيار & سو سيرى & 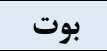 & داده & مسيرها \\
\hline.$- / \cdot 11 r$ & $-\cdot / Y F I$. &.$/ \cdot|r|$ & $\cdot \% r$ & $-\cdot / / \Delta F$. & $-\cdot / / D F Y$ & دلبستخى اجتنابى ־ خود كار آمدى ־ مهارت اجتماعى \\
\hline - & $-\cdot / Y 1 \cdot \Delta$ &.$/ \cdot 14$. & $-\cdot / \cdots+1$ & $-\cdot / \cdot \sqrt{9} 91$ & $-\cdot / \cdot v 9$. & دلبستگى اضطرابى ־ خود كار آمدى ־ مهارت اجتماعى \\
\hline$\cdot / \cdots r$ & $-\cdot / 1 r / 9$ & $\cdot / 1 \cdot r r$ & $\cdot / \cdot \Delta F$ &.$/ .491$ &.$/$ FFF & دلبستىى ايمن — خو دكار آمدى ־ مهارت اجتماعى \\
\hline
\end{tabular}

بيش بين منفى، و ســبك دلبسـتخى ايمن بيشبين مثبتى براى مهارت هاى اجتماعى كود كان با ناتوانىهاى ياد گيرى بوده است. اين يافتهها همسو با نتـايج يثزوهش هاى مختلف (||، Y| و س|) بوده اســت كه نشــان دادند مهارت اجتماعى در كود كان تحت تأثير روابط سـال هاى اوليه زندكى با مر اقبـان قرار مى گيرد؛ بنـابر اين لـازمـه افزايش مهارت اجتمـاعى افراد بـا ناتوانى هاى ياد گيرى، بهبود سـبك دلبستخى اسـت، همجنين اين يافته را مى توان اين كونه تبيين كرد كه ســبك هاى دلبســــى، شــيوه تعاملات اجتماعى و واكنش فرد نسبت به خود و ديخر ان را تعيين مى كنند. افراد با سـبك دلبسـته ايمن نسـبت به افراد نايمن، احسـاسـات و افكار خود را راحت تر با ديخران در ميان مى كذارند و اين موضسوع موجب مىشود كه آنها بتو انتـد بـا ديخران همدلى كنند. بنابراين، ارتباط اوليه ســالم والد و

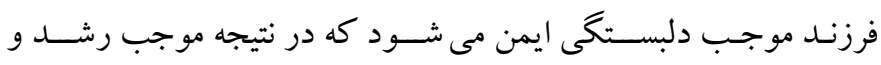

نتايج آزمون بوت اسـتربّ نشـان داد كه اثر غيرمسـتقيم سـبككهاى دلبستگى اجتنابى و اضطر ابى بر مهارت اجتماعى از طريق خود كار آمدى

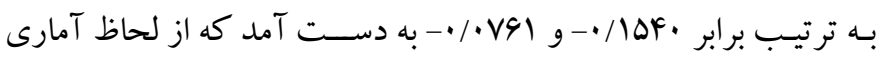
معنادار بودند؛ اما اثر غير مستقيم سبك دلبستكى ايمن بر مهارت اجتماعى از طريق خود كار آمدى از لحاظ آمارى، معنادار نبود.

\section{بحث و نتيجه تيرى}

اين يزوهش با هدف تدوين الكوى سـاختارى مهارت اجتماعى كود كان با ناتوانىهاى ياد گيرى بر اسـاس سبككهاى دلبسـتخى با نقش واسطهاى خود كار آمدى تحصيلى انجام شد. نتايج يزوهش نشان داد كه سبككهاى دلبسـتكى با مهارتهاى اجتماعى كود كان با ناتوانىهاى ياد گيرى مرتبط

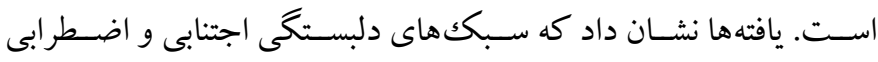


انسـانى و كر انبها در ييشـبرد اهداف جامعه و رســيدن بيش از ييش به جامعه آرمانى استفاده شود.

از محدوديت هاى اصلى اين يُزوهش مى توان به محدوديت جنسيت

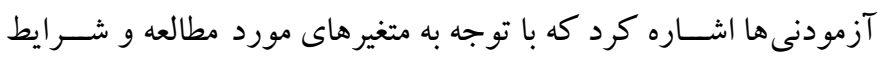

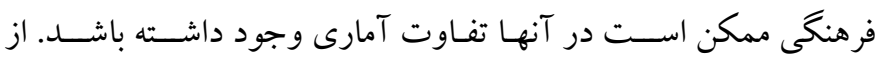
محدوديتهاى ديخر مطالعه حاضر اين بود كه فقط از برسشنامههاى فرم

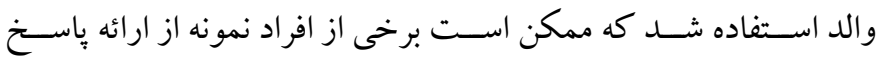
واقعى، خوددارى كرده باشـند؛ بنابر اين ييشـنهاد مى شـود از فرم معلم اين

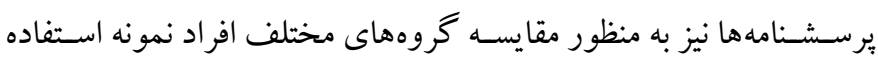
شـود. همجنين مى توان به عدم كنترل سطح تحصيلات و الدين و وضعيت اقتصـادى خانو اده اشـاره كرد كه مى تواند به عنوان عوامل تأثير كذار در

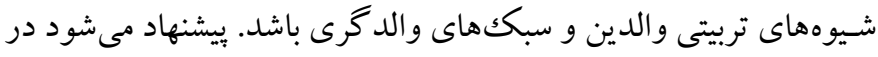

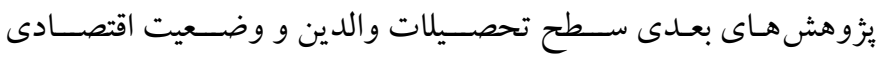
خانو ادهها نيز مورد كنترل قرار گيرد.

ملاحظات اخلاقى

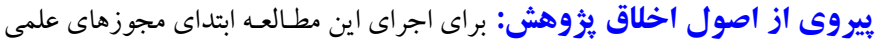

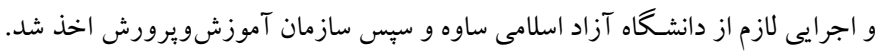

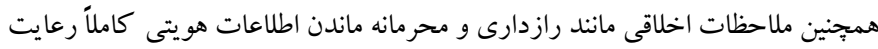
حامى مالى: اين مطالعه بدون حامى مالى و با هزينه شـخصى نويسـند كان انجام شـده

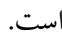

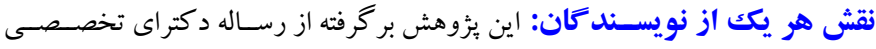

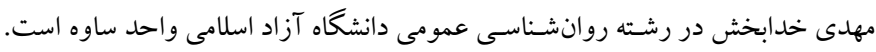

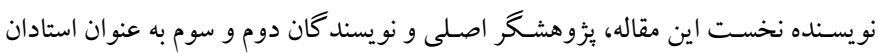
راهنما و مشاور بروزه نقش داشتهاند. تضـاد منافع: انجام اين ئزوهش براى نويسند گان هيج گُونه تعارض منافعى رابه دنبال نداشته است و نتايج آن كاملاً شفاف و بدون سو گيرى گز ارش شده بر است.

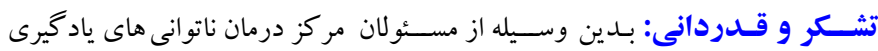

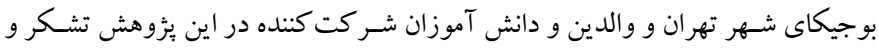
قدردانى مىشود.
شـكل گيرى مهارت هاى اجتماعى فرد در سـال هاى آينده خو اهد شــد و فرد در روابط بـين فردى، مهارت حسل مســئله، تصـميم گيرى، و و

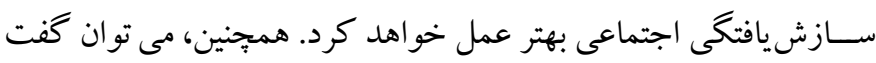

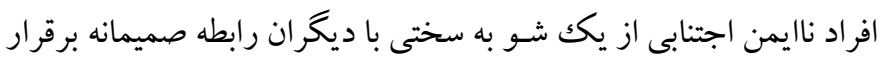

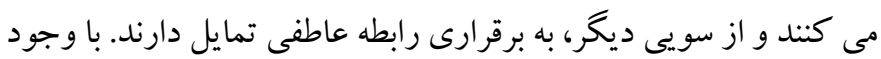

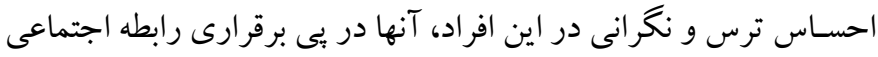
با ديخران هستند و اين مسئله موجب كاهش مهارت هاى اجتماعى در اين

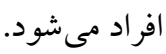
يافته ديخر اين يثزوهش كه حاصـل اجراى مدل اسـت، نشـان داد كه

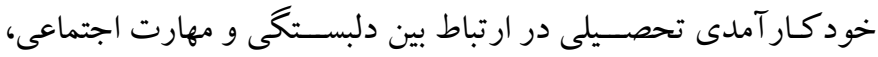

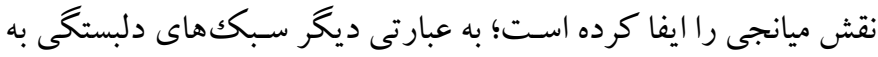
صـورت غير مســقيم و از طريق خود كار آمدى تحصـيلى، مهارتهاى

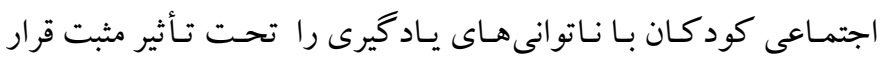

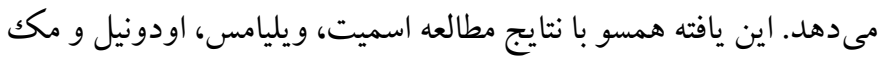

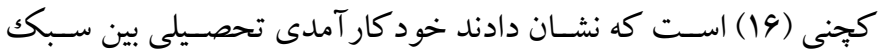

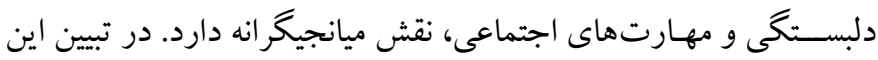
يافته مىتوان كفت، وقتى فرد به تو انايى هاى فردى و تحصيلى خود ايمان لهن

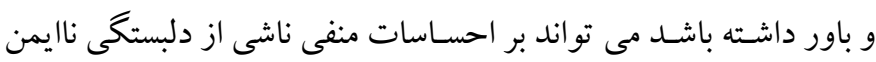
غلبه كرده و جرئت برقرارى روابط اجتماعى و بين فردى با ديخران را بيدا

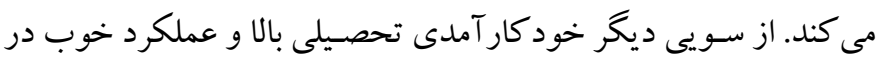

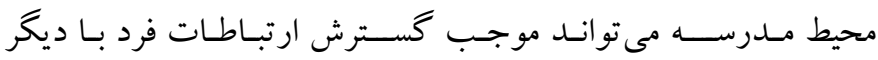
دانش آموزان شده و ديخران فرد با دلبستخى نايمن اجتنابى و اضطر ابى را به ارتباط اجتماعى با ديخر دانش آموزان، تشويق و ترغيب كند. در مجموع بـا توجـه بـه يافتهاى اين يُزوهش، توجه بيش از بيش به

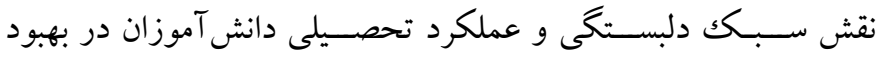

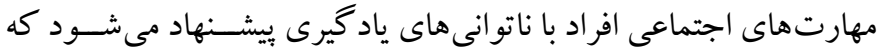

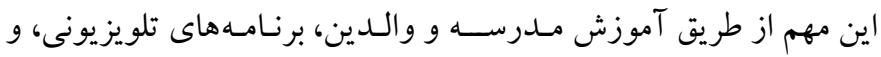

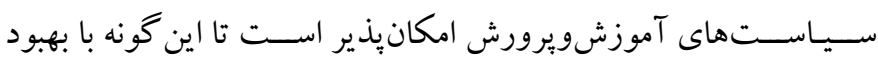

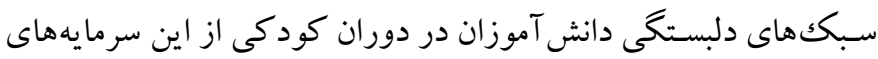




\section{References}

1. Ambika A, Vijayasamundeeswari P, David A. Effectiveness of planned teaching program among primary school teachers regarding awareness of learning disabilities in children. J Family Med Prim Care. 2019; 8(12):3845-3849. [Link]

2. Lyman RD, Sanders E, Abbott RD, Berninger VB. Translating Interdisciplinary Research on Language Learning into Identifying Specific Learning Disabilities in Verbally Gifted and Average Children and Youth. J Behav Brain Sci. 2017; 7(6):227-246. [Link]

3. Fletcher JM, Grigorenko EL. Neuropsychology of Learning Disabilities: The Past and the Future. J Int Neuropsychol Soc. 2017; 23(9-10):930-940. [Link]

4. Kenten C, Wray J, Gibson F, Russell J, Tuffrey-Wijne L, Oulton K. To flag or not to flag: Identification of children and young people with learning disabilities in English hospitals. J Appl Res Intellect Disabil. 2019; 32(5):1176-1183. [Link]

5. Baker-Ericzén MJ, Fitch MA, Kinnear M, Jenkins MM, Twamley EW, Smith L, et al. Development of the Supported Employment, Comprehensive Cognitive Enhancement, and Social Skills program for adults on the autism spectrum: Results of initial study. Autism. 2018; 22(1):6-19. [Link]

6. Vahedi M, Abbas G, Charkhabi P. The Effect of Teaching Concepts of Science in the Storytelling Method on Social Skills and Verbal Intelligence of Bilingual Pre-school Students. Culture Counseling. 2019; 10(38):81-100. [Persian] [Link]

7. Kuhn H, Cunha PR, Matthews NH, Kroumpouzos G. Body dysmorphic disorder in the cosmetic practice. $\mathrm{G}$ Ital Dermatol Venereol. 2018; 153(4):506-515. [Link]

8. Farhadi M, Mohagheghi H, Nesai Moghadam B. The relationship between attachment styles and student interpersonal problems: The role of mediating emotional intelligence. Razi J Med Sci. 2020; 27(1):73-84. [Link]

9. Bowlby J. Attachment and loss. Vol. 3: Loss. London: Hogarth. 1980. pp: 45-49.

10. Pyc MA, Rawson KA. Costs and benefits of dropout schedules of test-restudy practice: Implications for student learning. Applied Cognitive Psychology. 2011; 25(1):87-95. [Link]

11. Rafati, A., Tajik Esmaeli, S., \& Torbati, S. The role of attachment styles in students' communication skills and educational status. Educational Development of Judishapur, 2021, 12(1), 49-61. [Link]
12. Kim JI, Schallert DL, Kim M. An integrative cultural view of achievement motivation: Parental and classroom predictors of children's goal orientations when learning mathematics in Korea. Journal of Educational Psychology. 2010; 102(2):418-427. [Link]

13. Caplan B, Morgan J, Noroña AN, Tung I, Lee SS, Baker BL. The nature and nurture of social development: The role of 5-HTTLPR and geneparenting interactions. J Fam Psychol. 2019; 33 (8):927-937. [Link]

14. Arıkan F, Körükçü O, Küçükçakal A, Coşkun HS. Determination of Self-Efficacy, Body Image and Sexual Adjustment of Women with Breast Cancer. Eur J Breast Health. 2020; 16(4):282-289. [Link]

15. Klassen RM, Klassen JRL. Self-efficacy beliefs of medical students: a critical review. Perspect Med Educ. 2018; 7(2):76-82. [Link]

16. Smith G, Williams L, O'Donnell C, McKechnie J. A series of n-of-1 studies examining the interrelationships between social cognitive theory constructs and physical activity behavior within individuals. Psychol Health. 2019; 34(3):255-270. [Link]

17. Mafla AC, Divaris K, Herrera-López HM, Heft MW. Self-Efficacy and Academic Performance in Colombian Dental Students. J Dent Educ. 2019; 83(6):697-705. [Link]

18. Salsman JM, Schalet BD, Merluzzi TV, Park CL, Hahn EA, Snyder MA, et al. Calibration and Initial Validation of a General Self-Efficacy Item Bank and Short Form for the NIH PROMIS. Qual Life Res. 2019; 28(9):2513-2523. [Link]

19. Mohamadikarkani, A., Dortaj, F., \& Kiamanesh, A. The Effectiveness of Social-Emotional Skills with YCDI on Behavioural Disorders and Academic Performance of female high school students of district 1 Tehran city. Journal of Instruction and Evaluation, 2019, 12(45), 133-150. [Link]

20. Vayskarami, H., Mir Darikvand, F., Ghara Veysi, S., \& Solaymani, M. On the Relationship of Academic Self-efficacy with Academic Buoyancy: the Mediating Role of Basic Psychological Needs. Journal of Instruction and Evaluation, 2019, 12(47), 141-158. [Link]

21. Yu JH, Chae SJ, Chang KH. The relationship among self-efficacy, perfectionism and academic burnout in medical school students. Korean J Med Educ. 2016; 28(1):49-55. [Link]

22. Zahed Babelan A, Karimianpour G. The Relationship between Academic Optimism and Buoyance, the Mediator Role of Academic Self-efficacy. Educational 
and Scholastic Studies. 2020; 9(22):149-170. [Persian] [Link]

23. Assari S. General Self-Efficacy and Mortality in the USA; Racial Differences. J Racial Ethn Health Disparities. 2017; 4(4):746-757. [Link]

24. ARDALAN, E., \& HOSSEINCHARI, M. Predicting academic adjustment based on communication skills: the mediation role of self-efficacy. 2010, 6(17): 1-28. [Persian] [Link]

25. Sharifi H. P. Sharifi N. Principles of Psychometrics and Psychoanalysis. Ninth Edition. Tehran: Roshd. 2019; pp: 252-376. [Persian]

26. Elliott, S. N., \& Gresham, F. M. Social skills interventions for children. Behavior modification, 1993, 17(3), 287-313. [Link]

27. Abbasi Asfjir, A. A., \& Khatibi, F. The standardize Social Skills Rating System for Parents and Teachers, Preschool Level (SSRS-PT) Gresham \& Elliott in
AMOl. PSYCHOMETRY, 2016, 5(17), $77-96$. [Persian] [Link]

28. Kappenberg ES, Halpern DF. Kinship center attachment questionnaire: development of a caregivercompleted attachment measure for children younger than 6 years. Educ Psychol Meas. 2006; 66(5): 852- 573. [Link]

29. Soleimani, H, Bashash, L., Latifian, M. Psychometric properties of the Interpersonal Attachment Questionnaire for the middle age of childhood. Psychological methods and models. 2014; 4 (16): 41-63. [Persian] [Link]

30. Jinks, J., \& Morgan, V. Children's perceived academic self-efficacy: An inventory scale. The Clearing House, 1999, 72(4), 224-230. [Link]

31. Sabzian S, Ghadampour E, Mirderikvand F. Presenting a causal model of academic engagement and academic ethics with academic cheating: The mediating role of academic self-efficacy. Journal of school psychology. 2020; 8(4):217-227. [Persian] [Link] 